\title{
An Assessment of Apple Orchard Investments in South AFriCA UNDER UNCERTAINTY AND IRREVERSIBILITY
}

\author{
M A G Darroch, P A Hardman and G F Ortmann
}

School of Agricultural Sciences and Agribusiness, University of KwaZulu-Natal, Pietermaritzburg

\section{Abstract}

The competitiveness of the South African fresh apple export value chain can be improved if local farmers grow and market more new apple cultivars. An ex ante version of the Dixit-Pindyck investment model is used to assess how uncertainty and irreversibility associated with adopting the new Pink Lady cultivar rather than a traditional Golden Delicious cultivar will raise the hurdle rate required to trigger investment. Modified real hurdle rates reflecting the value of the option to delay investment estimated for both cultivars, are about double the real rate of five per cent that is often used in orthodox investment analyses. The Pink Lady investment seems to be relatively more profitable under the assumed conditions, but it also has a relatively greater variance in expected real annual net returns.

JEL L11, Q14, 17

\section{1}

\section{Introduction}

Key drivers of change in a firm's external environment include the launch of new products, the entry of lower-cost foreign competitors, government policy changes, interest rate and foreign exchange rate changes, and shifting consumer tastes (Thompson \& Strickland, 1998). Managers need to assess how these factors could affect a firm's future profitability and competitiveness, and then to evaluate what strategic actions must be taken to cope with them. Farmers who export fresh apples from South Africa (SA) have faced this challenge in adjusting to the deregulation of SA fresh apple marketing since 1994, and increasing export competition from rival producers in Chile and France. About 10 per cent of SA fresh apple producers faced liquidation of their businesses in 2000, and many failed to make a profit during 1999-2001, partly because of more intense international competition (Dall, 2001) and lower real world apple prices (O’Rourke, 2001). Interviews with key industry players ${ }^{1}$ at all levels in the SA fresh apple export value chain during March 2001 suggest that one particular threat currently facing the SA fresh apple industry is the failure to adopt new cultivars to meet changing consumer tastes (Hardman et al,, 2002).

Ongoing consolidation and the increasing price-making influence of multi-national retail grocery stores have allowed retailers to become increasingly selective about which types of apples they will stock (O'Rourke, 2001). The World Apple Report, which rates retailer perceptions about consumers' apple preferences, and the extent to which retailers plan to hold more of each cultivar in the next season, identifies Gala, Red Delicious, Braeburn, Fuji and Pink Lady as the five most popular cultivars for the future (World Apple Report, 2001). The Pink Lady (the trade mark for the Cripps-pink apple cultivar) was perceived to be the most popular of the new apple cultivars currently exported from SA, and 
at least 50 per cent of surveyed retailers planned to stock more Pink Lady apples in future. Retailers ranked Granny Smith and Golden Delicious - which together currently make up about 68 per cent of total SA apple exports - in sixth and tenth position, respectively. Clearly, the current basket of apples grown in SA seems out of line with future apple consumption trends, and could threaten the international competitiveness of the SA fresh apple industry. To counteract this threat, a systematic approach of introducing more emerging cultivars into the current SA apple basket by replanting more apple orchards at the end of their lifespan with these cultivars is probably required (Dall, 2001; Rabe, 2001). This strategy would probably create sustainable competitive advantage by supplying retailers with apples having better taste, shape, size and colour so that they successfully compete for the foreign consumer's United States (US) Dollar, Euro and/or British Pound, despite the wider availability of traditional and exotic fruits. This means that SA fresh apple producers must consider planting or replanting more orchards with apple cultivars that better match expected future consumer needs.

Decisions about which new apple cultivar to adopt, however, are complicated by uncertainty about the future prices, costs and yields from a new apple orchard investment that is typically productive for over 30 years. A regrettable choice can be costly, since, like most major capital-intensive projects, apple orchard investments are partially or completely irreversible - the start-up costs (approximately R90 000 per hectare at the time of writing) are at least partially sunk and cannot be fully recovered in the short-term (Dall, 2001; Dixit \& Pindyck, 1995). Postponing the investment would give SA apple farmers time to access more information about the expected prices, costs, and production techniques that may affect the desirability or timing of the investment. This implies that the option to postpone the investment may have value for SA apple farmers, despite the need to respond to increased export competition. When a farmer invests in a new apple orchard, that farmer forgoes or gives up the option to invest and cannot disinvest if market conditions change adversely. In effect, the value of this lost option is an opportunity cost that must be added to the direct cost of the orchard investment (Dixit \& Pindyck, 1994). Conventional methods of analysing the potential profitability of investments, like the Net Present Value (NPV) and Internal Rate of Return (IRR) techniques, must, therefore, be modified to account for this option value that raises the investment cost, or the required rate of return, that must be "hurdled" in order to "trigger" (justify) investing now.

Past studies have evaluated the competitiveness of SA fresh apple exports by comparing SA fresh apple production and market share performance with that of countries like Chile and France (Du Toit, 2000; Esterhuizen \& van Rooyen, 1999; Steenkamp, 1999; Van der Vyver, 1993), or have identified how to improve cooperation to make the SA fresh apple export value chain more competitive (Hardman et al., 2002). To the best of the authors' knowledge, there is no published research that assesses the viability of adopting a new apple cultivar for export from SA, rather than a traditional cultivar, taking into account investment uncertainty and irreversibility. The aim of this paper, therefore, is to assess whether or not investing in a Pink Lady orchard would be more profitable than investing in a Golden Delicious orchard, using a model proposed by Dixit and Pindyck (1994) that accounts for uncertainty and irreversibility by incorporating the value of the option to wait to invest. Both the Pink Lady and the Golden Delicious are seen as good apples for eating-out-of-hand and for cooking. This empirical study thus adds to the empirical applications of the Dixit-Pindyck model specifically in the context of perennial crops. Note, however, that Dixit and Pindyk (1994: 394) show that their "options" model can be used to evaluate a variety of investment problems, ranging from the development of natural-resource reserves (for example, offshore oil tracts) to the construction of new power plants by electric utilities. According to Turvey (2000), the real options approach to valuing capital projects is set to become the leading tool to assess capital investments under conditions 
of risk. Elmer et al. (2001) cite studies that use the Dixit-Pindyk model to evaluate investments in forest and land development and fertilizer factories, and then apply the model to assess future investment prospects for Texas grapefruit growers in the US.

The next section considers what expected income and cost changes are likely to occur when producers adopt a new apple cultivar, and then specifies the first research hypothesis for this study. Section 3 explains how to modify orthodox NPV and IRR analyses to account for the option to postpone any capital investment, and then specifies the second research hypothesis for this study. Section 4 describes the research methodology and SA data sources used to estimate by how much the direct cost of investment, or required rate of return, for both apple cultivars must be raised to reflect the option value. Section 5 presents the study results and compares trigger investment cost levels and rates of return for the two cultivars. Finally, a concluding section discusses the management implications of the results for SA fresh apple farmers.

\section{2}

\section{Expected changes in income and costs when a new apple cultivar is adopted}

Success or failure when adopting new apple cultivars to try and create sustainable competitive advantage can be judged by the extent to which adoption affects the firm's expected future income and costs. The cumulative difference that adopting a new cultivar makes to a farmer's expected income over the life-span of an apple orchard will depend on: (1) the difference in annual fresh apple yields; (2) the difference in the "packout" or distribution of apple quality; (3) the relative difference in the price per carton of apples; and (4) the comparative growth/decline in demand for each cultivar over time (Dall, 2001). Annual production costs can also vary from one cultivar to another as a result of different input (e.g. fertilizer, water, labour, machinery and chemicals) use, and modifications to methods used for pre- and post-harvest handling of the fruit. If the new cultivar needs additional storage facilities and unique atmospheric controlling devices to improve fruit colouring or to preserve taste, the firm's working capital requirements would change, causing higher interest charges if capital is borrowed. Investing in the new cultivar could also require that SA apple farmers have to purchase annually cultivar-specific inputs, whose real prices are uncertain over the orchard's life. Depending on how many additional facilities are needed and the firm's capacity to meet capital expenditure, the opportunities to convert to the Pink Lady may range from nil to extensive.

Producers may also incur relatively high search and information costs when they try to reduce the uncertainty about how the new cultivar will perform under SA conditions. Information costs are those expenses incurred when sourcing and buying information about new cultivars, such as details on nutrient, water and annual cold-unit requirements. If there are no applicable published records, growers may have to conduct their own, potentially expensive, in-field research and development trials. The administrative burden of collecting, sorting and processing such data adds to the total information costs as it requires management time, which has an opportunity cost (Calkins \& DiPietre, 1983: 115).

If farmers are typically risk-averse, they would prefer to adopt a farm plan that provides a satisfactory and more predictable level of income, even if this means sacrificing income on average (Hazell \& Norton, 1986: 216). Assuming that the expected income for a risky alternative is higher than for a certain outcome, sacrificed income amounts to an opportunity cost such that risk-averse farmers sacrifice increasingly more income by selecting more certain outcomes. Risk-averse producers, therefore, will forfeit potentially higher incomes associated with a new cultivar, but non-adoption shields them from potential losses due to disease, poor cultivar responses to climatic conditions (such as poor apple colouring), further changes in consumer tastes, and losses incurred while gaining operating and handling experience for the new cultivar. This means that 
the rate at which a new cultivar is adopted also depends on the level of risk-aversion of the chief decision-makers. To assess whether adopting the Pink Lady can potentially improve the financial standing of a typical SA fresh apple producer, this study formulates the following first hypothesis: Fresh apple farmers in $S A$ are likely to earn higher net returns per hectare by growing and exporting the Pink Lady cultivar than by growing and exporting the Golden Delicious cultivar.

\section{3}

\section{Modifying orthodox capital budgeting techniques to account for the option to postpone an investment}

Recent studies in the US show that the conventional expected NPV and IRR methods of capital budgeting that ignore uncertainty and irreversibility are likely to report biased NPV and IRR estimates, leading to inappropriate investment behaviour (Elmer et al., 2001; Collins \& Hanf, 1998; Purvis et al., 1995; and Dixit \& Pindyck, 1995). Biased NPV and IRR estimates are a consequence of incorrectly assuming that investors face a dichotomous "now" or "never" investment decision with no possibility to postpone the investment until a later time when more information might be available. In many cases, however, an investor can delay the project until later, and by so doing benefit from the opportunity to avoid downside risk if market conditions become unfavourable. The opportunity to avoid a "wrong" decision implies that the option to postpone the investment expenditure has value. Incorporating this option value into the orthodox NPV and IRR evaluations reduces the bias in NPV and IRR estimates and can help managers who face uncertainty to make optimal capital investment decisions (McDonald \& Siegel, 1986; Dixit \& Pindyck, 1994).

The performance of the Golden Delicious apple cultivar in SA is well documented, but there is uncertainty about the future performance of the Pink Lady cultivar as it has been introduced only recently into SA. By postponing the investment in a Pink Lady apple orchard, SA fresh apple producers could benefit from future breakthroughs in research and development that provide more knowledge about how to improve Pink Lady apple quality despite potentially wide variations in SA climatic conditions. Quality refers to postharvest characteristics such as shelf life, and also to aspects of fruit colouring, taste, shape and size, that can vary significantly between cultivars, and from year-to-year (Griessel, 2002). Postponing a Pink Lady apple orchard investment will also give SA apple producers more time to acquire information about whether or not the Pink Lady's current weighted average price premium (of about 18 per cent) over Golden Delicious apples will be sustainable over time.

A financial option confers upon the holder the right, but not the obligation, to buy (call option) or sell (put option) an asset, subject to certain conditions, within a specified period of time (Black \& Scholes, 1973). How much an option contract is worth is jointly determined by the current price of an underlying asset and by the degree of uncertainty about that price over the term of the option contract. McDonald and Siegel (1986), and later Dixit and Pindyck (1994), have used this options-pricing concept to analyse managers' capital investment behaviour under uncertainty and irreversibility. Analogously, investment opportunities through time are viewed as a series of choices (options) of whether to invest (exercise the option) or not. Investors are assumed to weigh up the value of investing now against the value of waiting to invest.

The value of an investment opportunity $(V)$ depends on the expected annual net returns from the investment $(R)$, the variance of the expected annual net returns $\left(\sigma^{2}\right)$, the sunk cost of initiating the investment $(K)$, and the real discount rate $(\rho)$. In orthodox NPV analysis, an investment would be acceptable if the present value of the discounted $R$ over the life of the project $(R / \rho)$ is greater than or equal to $K$. The point of indifference between investing now or not investing, ignoring the option to postpone the investment, is called the Marshallian trigger $(M)$, and occurs where $M=\rho K$ (or the annuity that yields a required real rate of return equal to $\rho$ over the life of the investment). If, however, 
an investor values the option to wait to invest, $M$ must be modified and adjusted upward to reflect the value of the foregone opportunity to postpone the investment. If the present value of the discounted expected annual net returns exceeds the modified investment trigger, the investment is acceptable, as the expected returns cover the full cost (direct cost plus opportunity cost) of making the investment. The gains from waiting in the case of apple orchard investments result from being able to avoid downside risk such as lower real apple prices and adverse climatic conditions. Dixit and Pindyck (1994: 142) derive the modified (optimal) investment trigger $(H)$ as

$$
H=\frac{B}{B-1} \rho K \text {. }
$$

The $H$ in equation (1) is greater than the Marshallian trigger, $M=\rho K$, by the factor $B /$ $(B-1)$ which is the "option value multiple". At $H$, the discounted expected annual net returns from investing in an apple orchard now are sufficiently high to cover both $K$ and the opportunity cost of not waiting. The parameter $B$ is a component of the function that Dixit and Pindyck (1994) derive to calculate the value of waiting, and it is jointly determined by $\rho$ and $\sigma^{2}$ as

$B=\frac{1}{2}\left[1+\sqrt{1+\frac{8 \rho}{\sigma^{2}}}\right]$.

A lower real discount rate, $\rho$, and/or greater uncertainty about the expected returns from investing (higher $\sigma^{2}$ ), reduces $\mathrm{B}$ and increases $B /(B-1)$. This increases the modified investment trigger, $H$, implying that the opportunity cost of exercising the option to invest has risen. A lower real discount rate increases the present value of later expected annual net returns and so encourages waiting, while greater uncertainty also increases the expected gains from waiting. In addition to the modified $H$ associated with the NPV method, Dixit (1992) proposes using the modified hurdle rate $\left(\rho^{\prime}\right)$ to evaluate the desirability of making an investment now. The $\rho^{\prime}$ incorporates the value of waiting by raising $\rho$ (the equivalent of the required rate of return, RRR, in the IRR method) by the value of the option value multiple, $B /(B-1)$, as shown in equation (3):
$\rho^{\prime}=\frac{B}{B-1} \rho$

where $B$ is again estimated by equation (2). Elmer et al. (2001) estimated that $\rho^{\prime}$ ranged from 19 to 29 per cent when they used real discount rates of between three and nine per cent to analyse the orchard investment decisions of Texas grapefruit farmers. Purvis et al. (1995) report $\rho^{\prime}$ estimates of two to three times the real discount rate of three per cent that they applied to evaluate the adoption of dairy housing technology in the US. Summers (1987) found that the managers of companies in the US were applying hurdle rates ranging from eight to 30 per cent (with a median of 15 per cent and mean of 17 per cent) in their investment decisions when nominal interest rates were about four per cent. Accounting for uncertainty and irreversibility is likely to make a difference to SA fresh apple producers that are considering investing in either a Pink Lady apple orchard or a Golden Delicious apple orchard in order to try and improve their competitiveness. The second hypothesis formulated for this study, therefore, is: Faced with uncertainty when deciding now whether to make an irreversible investment to grow and export the new Pink Lady cultivar or the traditional Golden Delicious cultivar, SA fresh apple farmers are likely to apply a relatively higher hurdle rate to the Pink Lady orchard investment because they have relatively less information about the performance of the new cultivar.

The a priori expectation is that SA fresh apple farmers who value the option of waiting for more information about the performance of the Pink Lady apple cultivar under SA conditions, will also apply hurdle rates higher than the current real discount rate $\left(\rho^{\prime}>\rho\right)$ before deciding to invest in a Pink Lady apple orchard. This hurdle rate ought to reflect the greater uncertainty associated with a Pink Lady apple orchard investment. The next section describes the research methodology and data sources used to estimate $B, H$ and $\rho^{\prime}$ at different $\rho$ levels for Golden Delicious and Pink Lady apple orchard investments in selected regions in SA. 


\section{4 \\ Research methodology and data sources}

Equation (2) in section 3 above shows that the parameter $B$ is jointly determined by the applied real discount rate, $\rho$, and the variance of the investment's expected annual net returns, $\sigma^{2}$. The researcher can set a range of plausible $\rho$ levels based on previous work such as Elmer $e t$ al. (2001) and recommendations made in financial texts like Barry et al. (1995). Two different approaches can be used to estimate $\sigma^{2}$ : The ex post approach involves collecting cross-sectional time-series data from investments similar to the capital investment under consideration, and then deriving $\sigma^{2}$ by averaging the variance of the expected annual net returns in the observed cases. The implicit assumption is that expected net returns are homoscedastic, and that past estimates of the variance of expected net returns are the best measure of future expected variance. There is, however, little reason to believe that the variance of the expected annual net returns for apple orchard investments will remain stable over time, especially given increasing competition from rival fresh apple exporters and the volatility of the Rand exchange rate. The expost approach is also ineffective when a new unproven opportunity to invest arises, having no predecessor from which to obtain the necessary time-series data. To overcome these constraints, an ex ante approach to the DixitPindyck model for estimating $\sigma^{2}$, and hence $B$, $H$ and $\rho^{\prime}$, was developed by Purvis et al. (1995) and is used in this paper.

First, define the natural log difference between the value of the opportunity to invest in an apple orchard now, $V_{t}$, and the potential value of that opportunity one period later, $V_{t+1}$, as $\Delta \ln V_{i} \equiv \ln V_{t}-\ln V_{t+1}$. The present value of this investment with expected annual net returns of $R_{t}$, at time $t$, and an instant later, at $t+1$, are then defined, respectively, as

$$
P V_{\mathrm{t}}=\sum_{\mathrm{j}=0}^{n} \frac{R_{\mathrm{t}}}{(1+\rho)^{\mathrm{j}}}
$$

and

$$
P V_{\mathrm{t}+1}=\sum_{\mathrm{j}=1}^{\mathrm{n}+1} \frac{R_{\mathrm{t}+\mathrm{i}}}{(1+\rho)^{\mathrm{j}-1}} .
$$

Following Dixit and Pindyck (1994: 175-212), the present value of the investment can be converted to the value of the equivalent opportunity to invest in perpetuity as

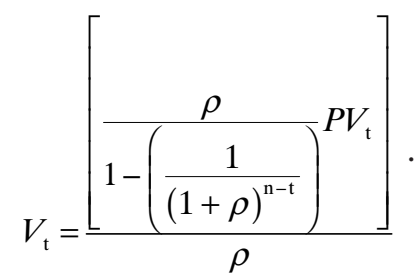

Similarly, $V_{\mathrm{t}+1}$ is given by

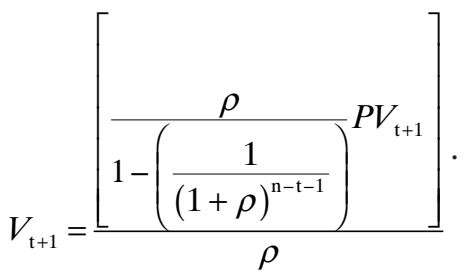

The numerator of equations (6) and (7) gives the annuity required to generate a stream of benefits equivalent to the present value of the orchard investment for either apple cultivar. Dividing this annuity by the discount rate, $\rho$, converts the stream of benefits to its present value (Purvis et al., 1995).

The difference between the natural logarithms of $V_{t}$ and $V_{t+1}$, or $\Delta l n V_{i}$, gives a discrete estimate of the change in the value of an apple orchard investment opportunity, where $j$ is the size of the sample over which this difference is calculated. Simulated over a large number of iterations, the expected $R_{t}$ from investing that are used to estimate $V_{t}$ and $V_{t+1}$ are assumed to follow a geometric Brownian motion process, which characteristically provides a discrete approximation of a geometric Brownian motion variate in the limit (Cox et al., 1979, cited by Purvis et al., 1995). Thus, the time path of this random process, with trend $u_{v}$ and variance $\sigma_{v}^{2}$, is estimated by measuring the movements that occur in infinitesimally small, discrete intervals over $N$ iterations. The trend variable, $u_{v}$, is estimated by 


$$
u_{\mathrm{v}} \approx \frac{1}{N} \sum_{\mathrm{j}=1}^{\mathrm{N}}\left[\Delta \ln V_{\mathrm{j}}\right]
$$

and then it is applied to estimate the variance of the value of the opportunity to invest, $\sigma_{v}^{2}$, as

$$
\sigma_{\mathrm{v}}^{2} \approx \frac{1}{N} \sum_{\mathrm{j}=1}^{\mathrm{N}}\left[\Delta \ln V_{j}-u_{v}\right]^{2}
$$

where $\mathrm{E}\left[\left(\ln V_{j}-u_{v}\right)^{2}\right]>>0$ (Purvis et al., 1995).

Using equations (1) to (9) inclusive above, the key parameters $B, H$ and $\rho^{\prime}$ were estimated separately for the Pink Lady and Golden Delicious apple orchard investments. An MSExcel spreadsheet model was first constructed to proxy the expected annual net returns per hectare $\left(R_{t}\right)$ over 35 years, the expected lifespan of typical Golden Delicious and Pink Lady apple orchards in the Western Cape and Langkloof regions of SA (Dall, 2001), using real annual net economic profit per hectare (accounting profit less estimated management costs, and less the opportunity cost of capital). Projected real apple prices and quality ("packout") estimates were based on a three-year data series for 1999-2001, while annual yield estimates were drawn from information submitted to the Deciduous Fruit Producers' Trust (DFPT) by its members in 2001. Variable cost estimates were based on real cost series data that were adjusted to reflect an orchard bearing 45 tons of apples per hectare per annum (the estimated industry average) (Dall, 2001). Four fresh apple exporters, two apple packers and two apple producers, selected from the Western Cape and Langkloof East regions between July 2001 and January 2002, provided three-year apple quality and price data, and apple production cost data for the Pink Lady apple cultivar.

Next, three real discount rates $(\rho$ s s) were used to generate different $\mathrm{PV}_{t}$ and $\mathrm{PV}_{t+1}$ scenarios for each apple orchard investment using equations (4) and (5). Initially, projected real annual $(2000=100)$ incomes and costs were discounted using $\rho$ equal to 5 per cent (the proxy for the rental rate of return to land in SA (Nieuwoudt, 1980)) to estimate each investment's present value in the current period, $\mathrm{PV}_{t}$, and one time period later, $\mathrm{PV}_{t+1}$. A comprehensive sensitivity analysis using packer charges that fell/rose by R25 per bin, different exporter commission rates, different Class I fruit pack-out percentages, and changes in the real prices of the two cultivars, was also conducted to estimate plausible upper and lower $\mathrm{PV}_{t}$ and $\mathrm{PV}_{t+1}$ bounds. Depending on the nature of the services offered, and the type of packing material used, packer charges range from R89 to R135 per bin, while exporter commission rates currently range from 3 to 12 per cent (Dall, 2001).

Assuming that the quality specifications for Class I apples remain the same, the year-onyear Golden Delicious and Pink Lady Class I percentage pack-out can change by up to seven and 20 percentage points, respectively (Griessel, 2002). Lower Class I percentage pack-outs often reflect unfavourable climatic conditions that are beyond the farmer's control, such as hail, apple yellowing, etc., that lead to poorer quality apples. Consultants advise Pink Lady apple producers to aim for a Class I apple pack-out above 40 per cent (a 29 per cent increase on current levels), but most farmers have yet to achieve this level (Dall, 2001). The real price of Golden Delicious apples was allowed to rise/fall by 10 per cent, while the real price of Pink Lady apples was varied upward by 10 per cent but downward by 20 per cent, to reflect an expected fall in the real price as supply is expected to rise relative to demand in future as new orchards start producing. The sensitivity analysis was then repeated using real $\rho$ 's of 3 , and 7 per cent, as plausible alternative levels of $\rho$ that SA fresh apple producers could face. Elmer et al. (2001) used real $\rho$ 's of 3, 6, and 9 per cent to analyse the investments in Texas grapefruit orchards.

Thirdly, the plausible upper and lower $\mathrm{PV}_{t}$ and $\mathrm{PV}_{t+1}$ bounds generated in the sensitivity analyses were used in a Monte Carlo simulation model to estimate upper and lower bounds for the values of the opportunity to invest in perpetuity, $V_{t}$ and $V_{t+1}$, for all three $\rho$ values as per equations (6) and (7). The estimate of the discrete difference, $\Delta \ln V_{i}$, was simulated using @ RISK software over $\mathrm{N}=5000$ iterations (Palisade Corporation, 2002) that selected PV and $\mathrm{PV}_{t+1}$ values at random from the range of 
values within their upper and lower bounds. Substituting these $5000 \Delta \ln V_{j}$ estimates into equations (8) and (9) produced estimates of $u_{v}$ and $\sigma_{v}^{2}$, respectively, for each cultivar. The latter variance statistic values were used to solve equation (2) for estimates of $B$ at all three $\rho$ values. Finally, the $B$ estimates were substituted into equations (1) and (3), respectively, to estimate the modified investment trigger, $H$, and the modified hurdle rate, $\rho^{\prime}$, for each $\rho$ value. The next section compares pack-out and price data, the annual net returns derived in the MSExcel spreadsheet, the sensitivity analysis results, and the estimates of $H$ and $\rho^{\prime}$, for the two apple cultivars.

\section{5}

\section{Results}

\subsection{Expected apple pack-outs, prices and annual net returns}

Table 1 shows that during 1999-2001, SA fresh apple farmers were paid, on average, R493 per ton (R6.16 per carton) more for Class I Pink Lady apples than for Class I Golden Delicious apples. Weighted according to pack-out, the average Pink Lady price per ton was 17.8 per cent higher, despite a greater percentage of Class I Golden Delicious fruit per ton. The relatively higher Golden Delicious Class I pack-out suggests that this cultivar is currently more suited to climatic conditions in SA, and also reflects the experience accumulated by managers and farm staff in producing and handling this cultivar. The higher Pink Lady weighted average income per bin is partly due to a higher share of Class II fruit (36 per cent of output) that was sold at R66 per ton more than Golden Delicious apples. Cartons of Class II apples are either sold in domestic municipal markets or are exported. A key question is: how long will the current price premium for Pink Lady apples continue before falling over time as Pink Lady apple supply increases with new plantings, or as current Pink Lady orchards mature? Class III apples are mostly used in EconoPaks sold by SA retail chain stores, or purchased by hawkers for informal markets. Consistent with the industry average, about 20 per cent of production for both cultivars was sent for processing at a price of R403 per ton.

\section{Table 1}

Golden Delicious and Pink Lady apple quality distribution and average real prices $(2000=100)$ in the Western Cape and Langkloof East regions of South Africa, 1999-2001

\begin{tabular}{|c|c|c|c|c|c|}
\hline \multirow[t]{2}{*}{ Apple class } & \multicolumn{2}{|c|}{ Golden Delicious } & \multicolumn{2}{|c|}{ Pink Lady } & \multirow[b]{2}{*}{$\begin{array}{l}\% \text { Difference } \\
\text { in price/ton }\end{array}$} \\
\hline & $\begin{array}{c}\text { Pack-out } \\
\%\end{array}$ & Price/ ton ${ }^{a}$ & $\begin{array}{c}\text { Pack-out } \\
\%\end{array}$ & Price/ ton ${ }^{a}$ & \\
\hline Class I & 52 & 1943 & 31 & 2436 & 25.3 \\
\hline Class II & 8 & 1732 & 36 & 1798 & 3.8 \\
\hline Class III & 21 & 292 & 14 & 292 & 0.0 \\
\hline Processed & 19 & $403^{b}$ & 19 & $403^{b}$ & 0.0 \\
\hline $\begin{array}{l}\text { Weighted average } \\
\text { price/ton }\end{array}$ & & 1289 & & 1519 & 17.8 \\
\hline
\end{tabular}

Notes: $\quad{ }^{a}$ Prices reflect producer average prices per ton (c.i.f. value less packer service charges, exporter commissions, freight, sea insurance, loadings and port costs).

${ }^{\mathrm{b}}$ Packer service charges, exporter commissions, freight, sea insurance, loadings and port costs are not incurred for processed apples. 
The Golden Delicious and Pink Lady apples are expected to have similar yields per hectare over 35 years in the main growing areas of the Western Cape and Langkloof East (Dall, 2001; Campbell, 2002; CIAMD, 2001). Estimated yields should typically rise to about 55-60 tons per hectare in year eight, and then fall gradually to about 33 tons per hectare by year 35 . Based on these expected yield levels, Table 2 indicates the expected real annual income and real costs per hectare $(2000=100)$ of Golden Delicious and Pink Lady apples in SA in years 0, 10 and 35 after orchard establishment. The higher expected gross income after service fees for the Pink Lady cultivar reflects its price premium and higher apple export percentage compared to the Golden Delicious cultivar, despite slightly higher storage, commission, marketing and freight costs. Pink Lady orchard establishment costs in year 0 [ $K$ in equation (1)] are R10 004 higher (R97 313 versus R87 309) at recommended tree planting densities per hectare, due essentially to the once-off royalty charges of R6 per tree that raise Pink Lady operating costs by R7.78 per ton. Based on the three-year series data, Pink Lady operating costs were, on average, about R56 per ton higher than for Golden Delicious due to higher expected harvesting and chemical spraying costs. Multiple picking is required for Pink Lady orchards, and this adds about R39.67 per ton to operating costs. There are also two extra chemical spray applications, as Pink Lady apples remain on the tree for longer.

\section{Table 2}

Estimated real income and real costs per hectare for Golden Delicious and Pink Lady apples $(2000=100)$ in the Western Cape and Langkloof East regions of South Africa for years 0, 10 and 35 after orchard establishment

\begin{tabular}{|c|c|c|c|c|c|c|}
\hline \multirow{2}{*}{\begin{tabular}{|l|} 
Cultivar \\
Year \\
\end{tabular}} & \multicolumn{3}{|c|}{ Golden Delicious } & \multicolumn{3}{|c|}{ Pink Lady } \\
\hline & $\mathbf{0}$ & 10 & 35 & $\mathbf{0}$ & 10 & 35 \\
\hline $\begin{array}{l}\text { Projected yields } \\
\text { (tons per } \mathrm{Ha} \text { ) }\end{array}$ & $\mathbf{0}$ & 61 & 33 & $\mathbf{0}$ & 61 & 33 \\
\hline $\begin{array}{l}\text { Gross income before } \\
\text { service fees }\end{array}$ & $\mathbf{0}$ & 125310 & 67791 & $\mathbf{0}$ & 142221 & 76939 \\
\hline Packer costs & 0 & 15831 & 8564 & 0 & 15831 & 8564 \\
\hline Packer storage charges & 0 & 8326 & 4504 & 0 & 9297 & 5030 \\
\hline Exporter commission & 0 & 8767 & 4743 & 0 & 10129 & 5480 \\
\hline Domestic marketing & 0 & 2292 & 1240 & 0 & 1528 & 826 \\
\hline Freight & 0 & 11520 & 6232 & 0 & 12864 & 6959 \\
\hline $\begin{array}{l}\text { Gross income after } \\
\text { service fees (1) }\end{array}$ & $\mathbf{0}$ & 78574 & 42508 & $\mathbf{0}$ & 92572 & 50080 \\
\hline \multicolumn{7}{|l|}{ Operating costs } \\
\hline Harvesting & 0 & 6471 & 3501 & 0 & 8952 & 4843 \\
\hline Fuel, oil \& lubricants & 2105 & 6572 & 3555 & 2105 & 6572 & 3555 \\
\hline Planting & 39829 & 0 & 0 & 39829 & 0 & 0 \\
\hline Fertilizer & 3646 & 2414 & 1306 & 3646 & 2414 & 1306 \\
\hline Weed control & 128 & 500 & 500 & 128 & 500 & 500 \\
\hline Orchard maintenance & 3252 & 3252 & 3252 & 3252 & 3252 & 3252 \\
\hline Irrigation & 9000 & 500 & 500 & 9000 & 500 & 500 \\
\hline Chemical sprays & 306 & 7907 & 4278 & 310 & 8157 & 4413 \\
\hline
\end{tabular}




\begin{tabular}{|c|c|c|c|c|c|c|}
\hline Salaries \& wages & 9448 & 11558 & 10494 & 9448 & 11558 & 10494 \\
\hline Depreciation & 8434 & 8434 & 8434 & 8434 & 8434 & 8434 \\
\hline Other & 11161 & 6695 & 4632 & 11161 & 6695 & 4632 \\
\hline Levies & 0 & 816 & 441 & 0 & 816 & 441 \\
\hline Royalties & 0 & 0 & 0 & 10000 & 0 & 0 \\
\hline Total operating costs & 87309 & 55119 & 40893 & 97313 & 57850 & 42370 \\
\hline \multicolumn{7}{|l|}{ Opportunity cost } \\
\hline Apples in cold storage & 0 & 685 & 371 & 0 & 918 & 496 \\
\hline Management fee & 0 & 2578 & 2578 & 0 & 3417 & 3417 \\
\hline Total opportunity cost & $\mathbf{0}$ & 3263 & 2949 & $\mathbf{0}$ & 4335 & 3913 \\
\hline Total activity cost (2) & 87309 & 58382 & 43842 & 97313 & 62185 & 46283 \\
\hline $\begin{array}{l}\text { Net economic profit } \\
(3)=(1)-(2)\end{array}$ & -87309 & 20192 & -1334 & -97313 & 30387 & 3797 \\
\hline
\end{tabular}

Notes: These figures are weighted estimates based on plausible pack-out distributions for the four apple quality classes over the years 1999-2001. Packing service charges were R120 per bin (R320 per ton), and packer storage facility costs were estimated at R136.89 and R150.14 per ton for Golden Delicious and Pink Lady, respectively (R5 per bin per week multiplied by the average number of weeks (17) that apples spent in cold storage during 2001, multiplied by the proportion of apples in cold storage). Exporter costs were calculated at 7.5 per cent of the average international selling price for each cultivar.

Given the period that apples remain in cold storage, the estimated average price per ton after service fees were deducted, and the estimated average real SA R150 bond market yield ${ }^{2}$ of 4.12 per cent at the time of writing (South African Reserve Bank, 2002), the expected annual opportunity cost of keeping apples in cold storage was R14.76 per ton for the Pink Lady, and R11.23 per ton for Golden Delicious apples. A fixed annual management fee of five per cent of gross income (Calkins \& DiPietre, 1983:115) derived from an average annual yield of 45 tons per hectare over the orchard life for both cultivars was also included as a proxy for the opportunity cost of management time. The higher annual fee for the Pink Lady orchard (R3 417 versus R2 578) reflects more management time spent supervising multiple pickings, and extra spray applications. Overall, the Pink Lady cultivar generates relatively more expected net economic profit per hectare of established orchard (over 50 per cent by year 10) - its higher income offsets higher expected costs per hectare. These results suggest that a Pink Lady apple orchard investment would be the relatively more profitable venture, and support the first hypothesis formulated for this study at the end of section 2 above.

\subsection{Sensitivity analyses of expected investment present values}

Table 3 summarises the results of the sensitivity analyses for the estimated lower bound, most likely, and upper bound values of $P V_{t}$ per hectare for the two apple orchard investments at each level of $\rho$. The corresponding $P V_{t+1}$ estimates, as expected, had slightly lower values than the $P V_{t}$ estimates (for the sake of brevity they are not reported here). The Pink Lady cultivar $P V_{t}$ (and $P V_{t+1}$ ) estimates are higher and have a larger range than the Golden Delicious estimates - the investment with higher annual returns appears to have greater inherent business risk. 


\section{Table 3}

Plausible lower bound, most likely and upper bound $P V_{t}$ estimates for Golden Delicious and Pink Lady apple orchard investments in the Western Cape and Langkloof East regions of South Africa using real discount rates $(\rho)$ of 3, 5 and 7 per cent, 2001

\begin{tabular}{|l|c|c|c|}
\hline Cultivar & \multicolumn{2}{|c|}{$\mathbf{P V}_{\mathbf{t}}\left(\mathbf{R}^{\prime} \mathbf{0 0 0}\right)$} \\
\hline & Lower bound & Most likely & Upper bound \\
\hline Golden Delicious (\%) & & & 186 \\
\hline$\rho=3$ & 90 & 138 & 138 \\
\hline$\rho=5$ & 50 & 94 & 116 \\
\hline$\rho=7$ & 10 & 63 & 370 \\
\hline Pink Lady (\%) & & & 290 \\
\hline$\rho=3$ & 180 & 289 & 235 \\
\hline$\rho=5$ & 120 & 205 & \\
\hline$\rho=7$ & 50 & 147 & \\
\hline
\end{tabular}

\subsection{Modified investment triggers and real hurdle rates}

Using the estimated $P V_{t}$ and $P V_{t+1}$ ranges and the@RISK simulation models to estimate equations (4) through (9), and equation (2), Table 4 shows that the estimated option value multiple, $B /(B-1)$, at $\rho=5$ per cent was 1.89 and 2.28 for the Golden Delicious and Pink Lady apple orchard investments, respectively. Orthodox NPV analysis of the Pink Lady orchard investment would estimate a Marshallian trigger, $M$, of R5 943 per hectare (the annuity that yields a real RRR of 5 per cent on the sunk cost, $K$, of R97 313, over the 35-year life of the orchard). Substituting 2.28 for $B /(B-1)$, and R5 943 for $M$ in equation (1) implies a modified investment trigger, $H$, of R13 550 per hectare. Substituting 2.28 for $B /$
$(B-1)$, and $\rho=5$ per cent into equation (3) gives an estimated modified hurdle rate for the Pink Lady apple orchard investment, $\rho^{\prime}{ }_{\mathrm{PL}}$, of 11.40 per cent. These estimates imply that for SA apple producers in the Western Cape and Langkloof East regions of SA who value the option to postpone an investment, a Pink Lady apple orchard must have an expected real IRR greater than 11.40 per cent, or, equivalently, have an expected present value of real annual net returns above R13 550 per hectare, in order to trigger investment expenditure. Similarly for $\rho=5$ per cent, potential Golden Delicious apple orchard investments in the Western Cape and Langkloof East must have an expected real IRR greater than 9.45 per cent, or have an expected present value of real annual net returns above R10 078 per hectare, in order to trigger investment expenditure. 


\section{Table 4}

Estimated modified investment triggers per hectare, and real hurdle rates, for Golden Delicious and Pink Lady apple orchard investments in the Western Cape and Langkloof East regions of South Africa, 2001

\begin{tabular}{|l|c|c|c|}
\hline Apple cultivar, investment triggers and hurdle rates & \multicolumn{3}{|c|}{ Real discount rate } \\
\hline Golden Delicious & $\rho=\mathbf{3} \%$ & $\rho=\mathbf{5} \%$ & $\rho=7 \%$ \\
\hline Option value multiple, $B /(B-1)$ & & & \\
\hline Marshallian investment trigger, $M$ & 2.25 & 1.89 & 1.69 \\
\hline Modified investment trigger, $H$ & $\mathrm{R} 4069$ & $\mathrm{R} 5332$ & $\mathrm{R} 6743$ \\
\hline Modified hurdle rate, $\rho_{\mathrm{GD}}^{\prime}$ & $\mathrm{R} 9155$ & $\mathrm{R} 10078$ & $\mathrm{R} 11396$ \\
\hline Pink Lady & $6.75 \%$ & $9.45 \%$ & $11.83 \%$ \\
\hline Option value multiple, B/(B-1) & & & \\
\hline Marshallian investment trigger, $M$ & 2.85 & 2.28 & 2.01 \\
\hline Modified investment trigger, $H$ & $\mathrm{R} 4535$ & $\mathrm{R} 5943$ & $\mathrm{R} 7516$ \\
\hline Modified hurdle rate, $\rho_{\mathrm{PL}}^{\prime}$ & $\mathrm{R} 12925$ & $\mathrm{R} 13550$ & $\mathrm{R} 15107$ \\
\hline
\end{tabular}

The Pink Lady apple orchard investment has an estimated modified hurdle rate that is higher than that of the Golden Delicious orchard investment at all levels of $\rho$, implying that SA fresh apple farmers who value the option to invest in either cultivar require a relatively higher expected rate of return for the Pink Lady apple orchard in order to invest now. These results support the second hypothesis formulated for this study towards the end of section 3 above. The relatively greater variance of the higher expected real annual net returns for the Pink Lady investment results in $\rho_{\mathrm{PL}}^{\prime}$ being greater than $\rho^{\prime}{ }_{\mathrm{GD}}$. For all values of $\rho$, the estimated $H$ and $\rho^{\prime}$ values are between one and two-thirds to nearly three times the size of the orthodox $M$ and $\rho$. These findings are consistent with the estimates in the US studies by Elmer et al. (2001), Purvis et al. (1995) and Summers (1987).

\section{6}

\section{Discussion and conclusion}

The need to grow and market more new apple cultivars has been identified as one potential solution to help improve the competitiveness of the SA fresh apple export value chain. Apple producers in SA who want to adopt the Pink Lady cultivar to try to improve their competitiveness must compare the expected gains against the expected additional costs, including the risk of making a wrong investment decision. Gains from investing depend on current and future apple demand, yields, quality and real prices, while additional costs include higher search and information costs, greater input use, and the foregone option to delay investing (option value). The main implication of this paper is that accounting for the option value will markedly affect the decision to adopt the Pink Lady cultivar instead of the Golden Delicious cultivar, given uncertainty about the Pink Lady cultivar's future performance, and that both investments are irreversible.

Accounting for uncertainty and irreversibility, the ex ante version of the Dixit-Pindyck investment model used in this paper indicates that a Pink Lady apple orchard investment has a higher modified investment trigger $(H)$, and a higher modified hurdle rate $\left(\rho_{\mathrm{PL}}^{\prime}\right)$, than an equivalent Golden Delicious orchard investment. This result is plausible, as the Pink 
Lady investment has higher expected real annual net returns over its life span, but also greater variance of the expected real annual net returns. Assuming an orthodox 5 per cent real discount rate $(\rho)$, the Pink Lady investment should yield an expected modified present value, $H$, of at least R13 550 per hectare and a real rate-ofreturn greater than the $\rho^{\prime}{ }_{\text {PL }}$ of 11.40 per cent, in order to trigger investment expenditure. The corresponding values for the Golden Delicious investment are $H$ of R10 078 per hectare and $\rho^{\prime}{ }_{\text {GD }}$ of 9.45 per cent. The modified real hurdle rates of 11.40 per cent and 9.45 per cent are over, or just below double, the orthodox real rate of 5 per cent. Differences of this level between orthodox and modified hurdle rates have also been reported in recent studies of the adoption of dairy housing technology, and investment in grapefruit orchards, in the US. Given the relatively higher expected net returns and more uncertainty associated with a Pink Lady orchard investment, a logical area for future research would be to interview SA fresh apple farmers to identify the extent to which farmers with different levels of risk-aversion and resource mixes would be prepared to diversify their apple cultivars.

To better manage production uncertainty, SA fresh apple farmers could try to build operating teams capable of managing climate and pest shocks that may affect the performance of the Pink Lady cultivar. Gaining accreditation in product quality and management assurance standards, such as Nature's Choice (developed in the United Kingdom by the Tesco supermarket group), HACCP (Hazard Analysis and Critical Control Point) and ISO 9000, can help to benchmark pack-outs, operating efficiency and financial performance against standard indicators of competitiveness (Turner \& Ortmann, 1999). Adopting these systems will also improve access to retail markets in Europe and North America where chain store managers are more willing to trade with suppliers that can guarantee product quality and food safety. Simultaneously, more research by institutions such as universities and Hortec (Pty) Ltd (a subsidiary of the DFPT) is needed on how to optimise the Class I pack-outs, enhance Pink Lady apple colouring, and to reduce the damage caused by pests, such as the codling moth. The recently re-introduced statutory R 15 per ton levy collected by exporters, municipal market authorities and local retailers on behalf of the DFPT is intended to fund research projects aimed at developing apple cultivars with more competitive features and robust performance potential under SA climatic conditions.

Those SA apple farmers with relatively less capital resources - due to lower real world apple prices, drought, the withdrawal of government export incentives, high real interest rates, and increased competition from other exporting rivals (Hardman et al., 2002) - have less scope to diversify by adopting new apple cultivars. These players should focus on lowering production and operating costs; for example, finding lower-cost specialised production inputs (such as new chemical sprays to prevent disease or to improve fruit ripening), trying to reduce apple transport costs through bulk product shipments, or improving orchard yields through better orchard maintenance programmes. In the long-run, however, retail consolidation trends are likely to continue or intensify, meaning that all players in the SA fresh apple export value chain will need to more closely track changing consumer needs, and respond by adjusting their production patterns.

Unfavourable fluctuations in exchange rates and declining real world apple prices are two sources of risk that producers must give special attention to when estimating the feasibility of adopting an emerging cultivar like the Pink Lady. Recent depreciation and subsequent recovery in the value of the Rand against the US Dollar, the Euro and the British Pound have highlighted the need for producers to manage exchange rate fluctuations better. Exploring ways to improve or reconstruct forward exchange rate contracts or minimum price contracts with packers and exporters could provide more protection to producers against short-term exchange rate risk. 


\section{Endnotes}

1 These players were Mr P Dall (Chairman, Deciduous Fruit Producers' Trust (DFPT)); Mr P Finn (Group Manager: Quality Services, Perishable Products Export Control Board); Mr A Rabe (Managing Director, DFPT); and Mr V Jensen (Chairman, Fresh Produce Exporters' Forum).

2 Average real SA R150 bond yields $=[((1$ $+\mathrm{i}) /(1+\mathrm{f}))-1]$ (adapted from Kay and Edwards, 1999: 325), where $i=$ average monthly R150 bond rate, and $f=$ average year-on-year monthly inflation rate based on the Consumer Price Index excluding interest on mortgage bonds (CPIX), over the period January 2001 to January 2002.

\section{References}

1 BARRY, P.J.; ELLINGER, P.N.; HOPKIN, J.A. \& BAKER, C.B. (1995) Financial Management in Agriculture, Interstate Publishers Inc.: Danville.

2 BLACK, F. \& SCHOLES, M. (1973) "The pricing of options and corporate liabilities", Journal of Political Economy, 81: 637-54.

3 CALKINS, P.H. \& DIPIETRE, D.D. (1983) Farm Business Management: Successful Decisions in a Changing Environment, MacMillan Publishing Co. Inc.: New York.

4 CAMPBELL, C. (2002) Personal communication, General Manager of Research, Deciduous Fruit Producers' Trust, Stellenbosch, South Africa.

5 CIAMD (2001) The Centre for International Agricultural Marketing and Development: Key Deciduous Fruit Statistics, 3-7, Deciduous Fruit Producers' Trust: Paarl.

6 COLLINS, R.A. \& HANF, C. (1998)

"Evaluations of farm investments: Biases in net present value estimates from using quasideterministic models in an uncertain world", Agricultural Finance Review, 58: Article \# 6. http://aem.cornell.edu/special_programs/afr/. (Accessed 15 February 2002.)

7 DALL, P. (2001) Personal communication, Chairman, Deciduous Fruit Producers' Trust, Villiersdorp, South Africa.
8 DIXIT, A.K. (1992) "Investment and hysteresis", Journal of Economic Perspectives, 7: 107-32.

9 DIXIT, A.K. \& PINDYCK, R.S. (1994) Investment Under Uncertainty, Princeton University Press: New York.

10 DIXIT, A.K. \& PINDYCK, R.S. (1995) “The options approach to capital investments", Harvard Business Review, 73: 105-15.

11 DU TOIT, C. (2000) "Nasionale mededingende voordeel: Die Suid-Afrikaanse appelbedryf", Unpublished MScAgric thesis, Stellenbosch: University of Stellenbosch, South Africa.

12 ELMER, N.A.; THUROW, A.P.; JOHNSON, J.L. \& PARR ROSSON, C. (2001) "An ex ante assessment of investment in Texas grapefruit under uncertainty", Journal of Agricultural and Applied Economics, 33: 391-401.

13 ESTERHUIZEN, D. \& VAN ROOYEN, C.J. (1999) "How competitive is agribusiness in the South African food commodity chain?", Agrekon, 38 (4): 744-54.

14 GRIESSEL, H. (2002) Personal communication, Quality Manager, Tru-Cape Trading (Pty) Ltd., Grabouw, South Africa.

15 HARDMAN, P.A.; DARROCH, M.A.G. \& ORTMANN, G.F. (2002) "Improving cooperation to make the South African fresh apple export value chain more competitive", Journal on Chain and Network Science, 2(1): 61-72.

16 HAZELL, P.B.R. \& NORTON, R.D. (1986) Mathematical Programming for Economic Analysis in Agriculture, MacMillan Publishing Co. Inc.: New York.

17 KAY, R.D. \& EDWARDS, W.M. (1999) Farm Management, WCB/McGraw-Hill: Boston.

18 MCDONALD, R. \& SIEGEL, D.R. (1986) "The value of waiting to invest", Quarterly Journal of Economics, 101: 707-28.

19 NIEUWOUDT, W.L. (1980) "Value and rent of farm land", The South African Journal of Economics, 44: 389-97.

20 O'ROURKE, D. (2001) President, Belrose Inc., Pullman, Washington, USA. Paper presented at the World Apple and Pear Association Meeting, August 2. Belgium.

21 PALISADE CORPORATION (2002). http:// www.palisade.com. (Accessed 15 March 2002.)

22 PURVIS, A.; BOGGESS, W.G.; MOSS, C.B. \& HOLT, J. (1995) "Technology adoption decisions under irreversibility and uncertainty: An ex ante approach", American Journal of Agricultural Economics, 77: 541-51. 
23 RABE, A. (2001) Personal communication, Managing Director, Deciduous Fruit Producers' Trust, Paarl, South Africa.

24 SOUTH AFRICAN RESERVE BANK. (2002) South African Reserve Bank Quarterly Bulletin, March, South African Reserve Bank: Pretoria.

25 STEENKAMP, E. (1999) "Strategic market research on South African exports: A focus on agriculture", Working Document. Geneva: The National Department of Agriculture, South Africa.

26 SUMMERS, L.H. (1987) "Investment incentives and discounting of depreciation allowances", in The Effects of Taxation on Capital Accumulation, Feldstein, M. (ed.) University of Chicago Press: Chicago.

27 THOMPSON, A.A. \& STRICKLAND, A.J. (1998) Crafting and Implementing Strategy: Text and Readings, Irwin/McGraw-Hill: Boston.
28 TURNER, C.R. \& ORTMANN, G.F. (1999) "Quality management amongst South African agribusiness firms: The role of ISO 9000 quality assurance standards", South African Journal of Economic and Management Sciences, NS 2(3): 451-75.

29 TURVEY, C. (2000) "A primer on the real options' valuation of capital projects in agriculture", AgriFood 2000 Congress Proceedings, Agribusiness Society of Australia: Melbourne, Australia, August 16-17, 2002: $37-$ 52.

30 VAN DER VYVER, A. (1993) "An analysis of the US import market for fresh apples with specific reference to opportunities for South Africa", South African Journal of Economic and Management Sciences, 10: 34-46.

31 WORLD APPLE REPORT (2001) "Retailers know what they want", The World Apple Report, 8, Belrose Inc.: Pullman, Washington: 1-7. 